XX.

Aus dem sero-therapeutischen Institut in Wien.

\title{
Ueber die Bedeutung der Lipoide für die antihämolytische Wirkung des Serums:
}

\author{
Von \\ Michael von Eisler.
}

I.

Durch die fast gleichzeitig erschienenen Arbeiten von Overton (1) und H. Meyer (2) über die Theorie der Narkose wurde die Aufmerksamkeit auf die lipoiden Bestandtheile der Zellen gelenkt.

Seitdem nun Ransom (3) in einer im Laboratorium von H. Meyer ausgeführten Arbeit gefunden hatte, dass derjenige Körper des normalen Serums, welcher die rothen Blutkörperchen vor der lösenden Wirkung des Saponins schützt, ätherlöslich ist resp. diesen Schutzstoff mit dem Cholesterin identificirt hatte und so zum ersten Male einen seiner chemischen Natur nach wohl charakterisirten Antikörper dargestellt hatte, sind eine Reihe von Arbeiten erschienen, die sich mit den Lipoiden und ihrer Wirkung bei der Hämolyse beschäftigen.

So führte Noguchi (4) die schützende Wirkung von Serum und Milch gegenüber der Hämolyse durch Solanin, Saponin, Agaricin und Tetanolysin auf den Cholesteringehalt dieser Flüssigkeiten zurück.

P. Th. Müller (5) fand nach Fällung des Pferdeserums mit Alkohol in dem alkoholischen Extract einen das Tetanolysin stark hemmenden Körper, während der in $\mathrm{NaCl}$ aufgenommene Eiweissniederschlag nach seiner Angabe keine schützende Wirkung mehr besass.

Einen alkohollöslichen, das Tetanolysin hemmenden Körper fand auch H. Sachs (6); dagegen konnte er für das Staphylolysin durch Behandlung des Serums mit Alkohol keinen Antikörper erhalten.

Ferner haben Detre und Sellei (7) sowohl bei der Hämolyse durch Sublimat als bei der durch das Tetanustoxin eine Schutzwirkung durch die Lipoide des Serums constatiren können.

Ausser durch die Lipoide des Serums gelingt es, wie Landsteiner und ich (8) zeigen konnten, auch durch Petroläther und AethylätherExtracte aus rothen Blutkörperehen sowohl die Hämolyse durch Serum als auch durch Tetanolysin zu hemmen resp. aufzuheben.

Durch Herstellung künstlicher Membranen aus Cholesterin-Lecithingemischen gelang es Pascuchi (9), Hemmung der Hämolyse durch 
verschiedene Gifte, als Solanin, Saponin, Tetanolysin, Cobragift zu erzielen, und zwar wuchs die Sebutzkraft dieser Membranen mit deren Cholesteringehalt.

Da nun, wie zuerst Kraus und Clairmont (10) ausfuhrlich zeigten, normale Sera eine ganz bedeutende antihämolytische Wirksamkeit gegen die verschiedensten Bakterienhämolysine besitzen, schien es mir von besonderem Interesse, zu untersuchen, worauf diese antihämolytische Wirksamkeit des Serums zurückzuführen sei, ob es sich dabei wirklich nur um die Lipoide des Serums handle, wie von Detre und Sellei behauptet wurde, oder ob nicht auch wirklichen Antikörpern gleichzustellende Substanzen, nämlich Eiweisskörper, bei dieser Wirkung betheiligt wären. Diese letztere Annahme schien mir schon wegen der Specifität resp. Vielheit der normalen Antihämolysine, welche von verschiedenen Autoren [Kraus und Clairmont(11), Neisser (12), Sachs (13)] durch Versuche nachgewiesen wurde, sehr wahrscheinlich, eine Thatsache, die sich mit der Annalime einer reinen Lipoidwirkung absolut nicht in Einklang bringen lüsst.

Vor einiger Zeit veröffentlichte lntersuchungen (14), in denen es mir gelungen war, durch Extraction des Serums mit Alkohol oder Aether eine das Tetanolysin hemmende Substanz zu gewinnen, welche sich jedoch gegen das Jysin des Staphylococeus und des Vibrio Nasik unwirksam erwies, liessen bereits auch beim Tetanolysin auf das Vorhandensein cines eiweissartigen Antihämolysins schliessen.

Im Verlaufe derartiger Untersuchungen, durch die es gelang, eine alkohol- resp. ätherlüsliche Substanz $\%$ finden, welche sich so vielen Blutgiften gegenüber als Schutzkörper erwies, kam man vielleicht dazu, die Bedeutung dieses Kürpers zu überschätzen bezw. ihn als alleinige Lrsache der Schutzwirkung des Serums anzuselıen. Wenn nun auch diese Annahme für eine Reihe von Blutgiften, als deren Repräsentant in meinen Versuchen das Saponin gewählt wurde, zutrifft, kann dieselbe doch keine so allgemeine Giltigkeit beanspruchen. Denn ganz abgesehen vom Staphylolysin, für welches im Serum überhaupt keine fettartigen schützenden Körper existiren, ist auch die antitetanolytische Wirkung des Serums, obwohl daraus gewonnene Alkohol- oder Aetherextracte schützen, doch auf einen Liwcisskörper zurückzuführen. Das im Serum vorhandene Iipoid (Cholesterin) scheint bei dessen Schutzwirkung in diesem Falle gar kcine oder nur eine untergeordnete Rolle zu spielen, die Schutzwirkung des Serums beruht vielmehr auch beim Tetanolysin auf eine den andern Antikörpern gleichzustellende Substanz und nicht auf einem Lipoid.

Dieser das Blutgift des Tetanusbacillus hemmende Körper verhält sich, wie in den folgenden Versuchen gezeigt wird, gauz analog den übrigen bekannten Antikörpern, und nur durch diesen Befund findet die Specifität dieser Wirkung eine ungezwungene Erklärung, während die von den Jjipoiden resp. dem Cholesterin des Serums ausgeübte Wirkung jeder Specifität entbehrt; es ist ja wohl auch nicht gut denkbar, dass die Specifität durch einen verhältnismässig so einfach gebauten Körper wie das Cholesterin bedingt wäre. 
Durch die interessante Arbeit von Mausmann (15), von der noch die Rede sein soll, wurde übrigens nachgewiesen, dass die Cholesterine verschiedenster Herkunft, auch pflanzlichen Lrsprungs, sich in ihrer hemmenden Wirkung gegen Saponin nicht wesentlich unterscheiden. Ferner liesse sich durch die Annahme eines fettartigen Antitetanolysins auch nicht die oft ziemlich bedeutende Differenz in der Wirkung der Sera verschiedener Thierarten und selbst einzelner Sera derselben Thierart erklären, da ja der Cholesteringehalt der Sera nur geringen Schwankungen unterliegt. So fand z. B. Abderhalden (16) bei seinen Analysen verschiedener normaler Pferdesera sowohl für das Cholesterin als auch für die übrigen Lipoide des Serums Werthe, die ungefähr um das Doppelte schwankten, die hemmende Wirkung war jedoch zuweilen um den hundertfachen Werth verschieden, indem ich normale Pferdesera fand, die das Tetanolysin erst in Mengen von $0,5-0,1 \mathrm{ccm}$ hemmten, während andere noch in Mengen von $0,001 \mathrm{ccm} z u$ schützen im Stande waren. Diese Ueberlegungen führen also zu der schon oben ausgesprochenen $A$ nnahme eines eiweissartigen Antitetanolysins, zu deren Stütze die folgenden Versuche dienen mögen.

\section{Wirkung der verschiedenen Eiweisskörper des Serums.}

Aus normalem Pferdeserum, das sowohl das Tetanolysin als auch das Staphylolysin hemmt, wurde das Globulin mit dem gleichen Volumen gesättigter Ammonsulfatlösung gefällt, der Niederschlag gut alogepresst und in der dem Serum entsprechenden Menge Aqua dest. gelöst. Aus dem Filtrate der ersten Fällung wurde durch Eintragung von festem

T a belle I.

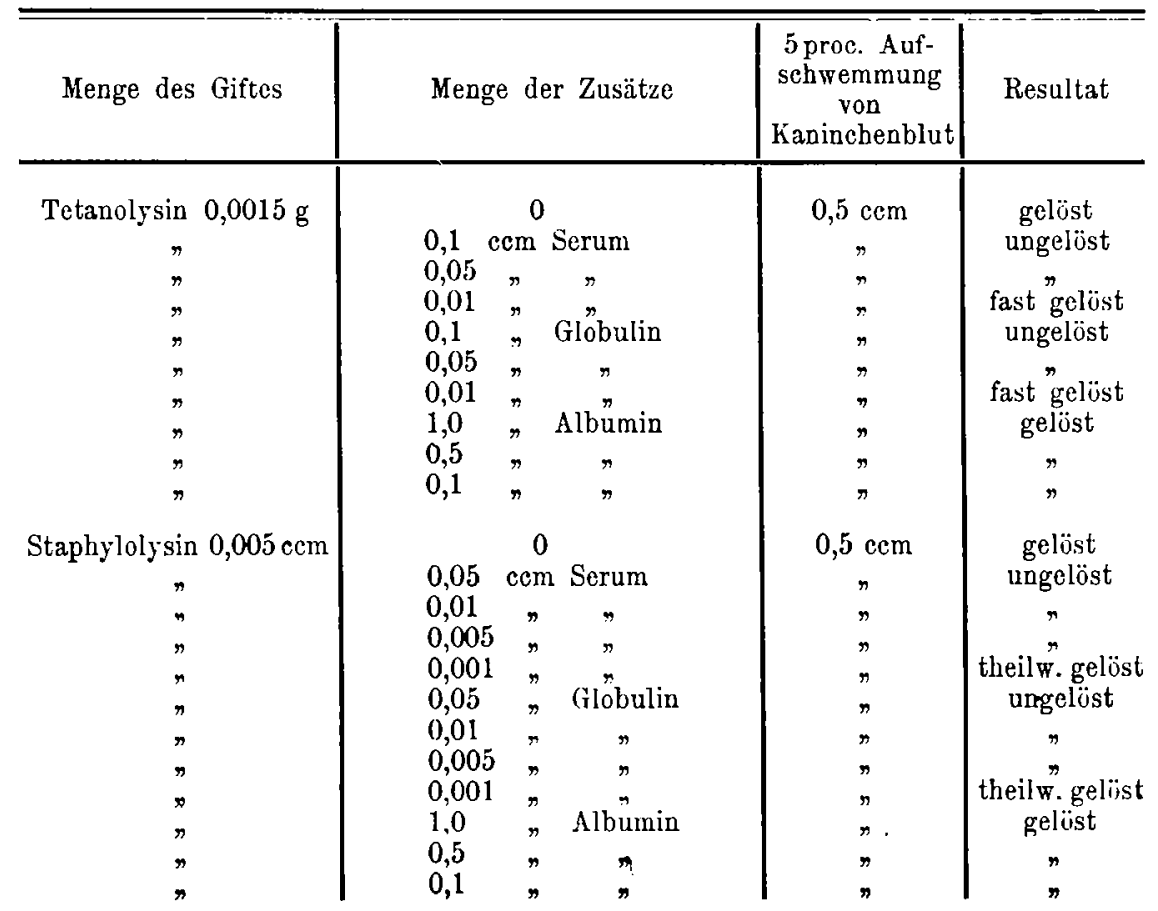


Ammonsulfat bis zur vollständigen Sättigung das Albumin gewonnen und mit diesem Niederschlag in derselben Weise wie mit dem Globulin verfahren. Die beiden so gewonnenen Eiweissfractionen des Serums wurden nun auf Hemmung des Staphylo- und Tetanolysins geprüft. Die Versuchsanordnung war dabei dieselbe, wie sie bereits in früheren Untersuchungen angewendet worden war, $d . h$. die lösende Dosis des Giftes wurde mit dem Serum resp. den beiden Eiweissfractionen 20 bis 30 Minuten im Brutofen digerirt, hierauf erfolgte der Zusatz der Blutaufschwemmung. Abgelesen wurde jedes Mal nach zweistündigem Aufenthalt im Brutschrank (Tab. I).

Sowohl beim Tetanolysin als auch beim Staphylolysin wirkte also das Globulin ebenso stark hemmend wie das Serum, das Albumin hingegen war beiden Giften gegenüber unwirksam.

\section{Einwirkung von Fermenten auf das Globulin.}

Die weiteren Versuche wurden nun mit der so ausgewertheten Globulinlösung, die ja die volle Wirksamkeit des Serums besass, ausgeführt. Je $10 \mathrm{ccm}$ dieser Lösung wurden mit dem gleichen Volumen einer 1/4-Normal-Salzsäure und der entsprechenden Pepsinmenge, ferner mit dem gleichen Volumen einer 0,8 proc. Sodalösung und Trypsin, eine dritte Probe mit dem gleichen Volumen 0,8 proc. Sodalösung und Steapsin Grübler versetzt. Alle drei so beschickten Röhrchen wurden hierauf in den Brutschrank gestellt. Nach verschiedenen Zeiten, 1, 4, 7 und 24 Stunden, wurden den Röhrchen Proben entnommen, neutralisirt und dann auf Hemmung der Hämolyse geprüft.

Aus dem in Tabelle II und III wiedergegebenen Versuche ergiebt sich, dass schon nach kurzer Einwirkung der Pepsin-Salzsäure sowohl das Antitetano- als auch das Antistaphylolysin stark geschädigt, nach etwas längerer Einwirkung so gut wie vollständig verschwunden war, und zwar ging diese Abschwächung parallel mit der Abnahme des coagulablen Eiweisses in der Globulinlösung. Bei den mit Trypsin versetzten Proben war infolge der schweren Angreifbarkeit des Globulins durch: Trypsin keine Abnahme des coagulablen Eiweisses und dementsprechend auch keine Einbusse der antihämolytischen Wirkung zu constatiren. Selbst nach 48 stündiger Einwirkung des Trypsins war die schützende Wirkung des Globulins vollkommen erhalten geblieben. Auch mit Steapsin wurden Proben nach 2, 5, 8 und selbst 18 tägiger Einwirkung untersucht, ohne dass die hemmende Wirkung der Globulin]ösung im Geringsten abgenommen hätte. Die fettspaltende Wirkung des Steapsins wurde an Proben mit Milch festgestellt, die mit Lakmustinctur gefärbt durch Rothwerden das Vorhandensein freier Fettsäuren anzeigten.' Dementsprechend zeigte sich auch, dass die früher alkalisch reagirenden Proben des Globulins nach einiger Zeit neutral, später sogar sauer reagirten.

Selbstverständlich kann eine Bakterienentwicklung ausgeschlossen werden, da die Globulinlösungen carbolisirt waren. Wurde Globulin statt bei alkalischer bei neutraler Reaction der Einwirkung des Steapsins ausgesetzt, so wurde das gleiche Resultat erhalten. 
M. v. Eisler,

Tabelle II.

\begin{tabular}{|c|c|c|c|}
\hline Menge des Giftes & $\begin{array}{l}\text { Menge des rit Fermenter } \\
\text { behandelten Globulins }\end{array}$ & $\begin{array}{l}5 \text { proc. Auf- } \\
\text { schwemmung } \\
\text { von } \\
\text { Kaninchenblut }\end{array}$ & Resultat \\
\hline $\begin{array}{c}\text { Tetanoly sin } 0,0015 \mathrm{~g} \\
" \\
" \\
" \\
" \\
" \\
" \\
" \\
"\end{array}$ & 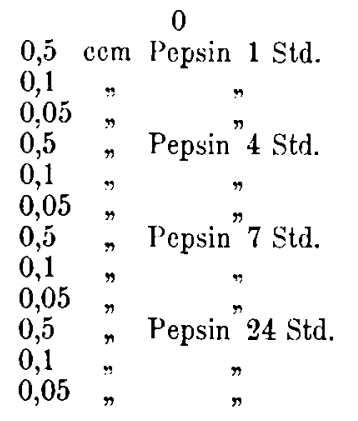 & $\begin{array}{c}0,5 \mathrm{cem} \\
" \\
" \\
" \\
" \\
" \\
" \\
" \\
" \\
"\end{array}$ & $\begin{array}{l}\text { gelöst } \\
\text { theilw. gelöst } \\
\text { gelöst } \\
\text { fast" gelöst } \\
\text { gelöst } \\
\text { fast gelöst } \\
\text { gelüst } \\
\text { fast gelöst } \\
\text { gelöst } \\
\text { " }\end{array}$ \\
\hline $\begin{array}{c}\text { Tetanolysin } 0,0015 \mathrm{~g} \\
" \\
" \\
" \\
" \\
" \\
" \\
" \\
" \\
"\end{array}$ & 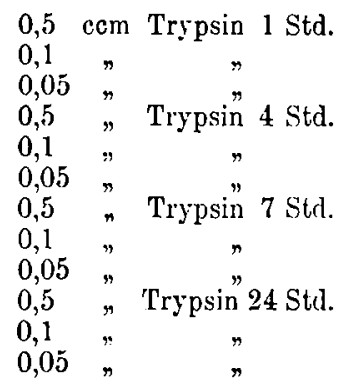 & $\begin{array}{c}0,5 \mathrm{ccm} \\
" \\
" \\
" \\
" \\
" \\
" \\
" \\
" \\
"\end{array}$ & $\begin{array}{l}\text { ungelöst } \\
" \\
" \\
" \\
" \\
" \\
" \\
" \\
" \\
"\end{array}$ \\
\hline $\begin{aligned} & \text { Tetanolysin } 0,0015 \mathrm{~g} \\
&= \\
& \\
& \\
& \\
& " \\
& " \\
& " \\
& "\end{aligned}$ & 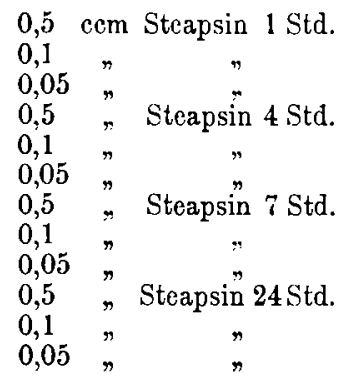 & $\begin{array}{c}0,5 \mathrm{ccm} \\
" \\
" \\
" \\
" \\
" \\
" \\
" \\
" \\
"\end{array}$ & $\begin{array}{c}\text { ungelöst } \\
" \\
" \\
" \\
" \\
" \\
" \\
" \\
"\end{array}$ \\
\hline
\end{tabular}

Ein fast ebenso starker Verlust des Antihämolysins wie bei der Pepsinsalzsäure-Verdauung trat übrigens auch schon dann cin, wenn das Globulin bloss mit $1 / 4$-Normalsalzsäure allein versetzt und in den Brutschrank eingestellt wurde. Nach einstïndiger Hinwirkung der Süure bei $36^{\circ}$ hatte das Globulin ein milchiges Aussehen angenommen, d.h. es hatte sich Acidalbumin gebildet, und die schützende Wirkung war fast verloren gegangen (Tab. IV).

Alkali allein hatte nicht diese schädigende Wirkung auf das Globulin, denn Proben, die mit dem gleichen Volumen 0,8 proc. Sodalösung versetzt fünf Stunden im Brutschrank gehalten wurden, hemmten sowohl Tetano- als auch Staphylolysin noch genau so stark wie vorher (Tab. V). 
Tabelle III.

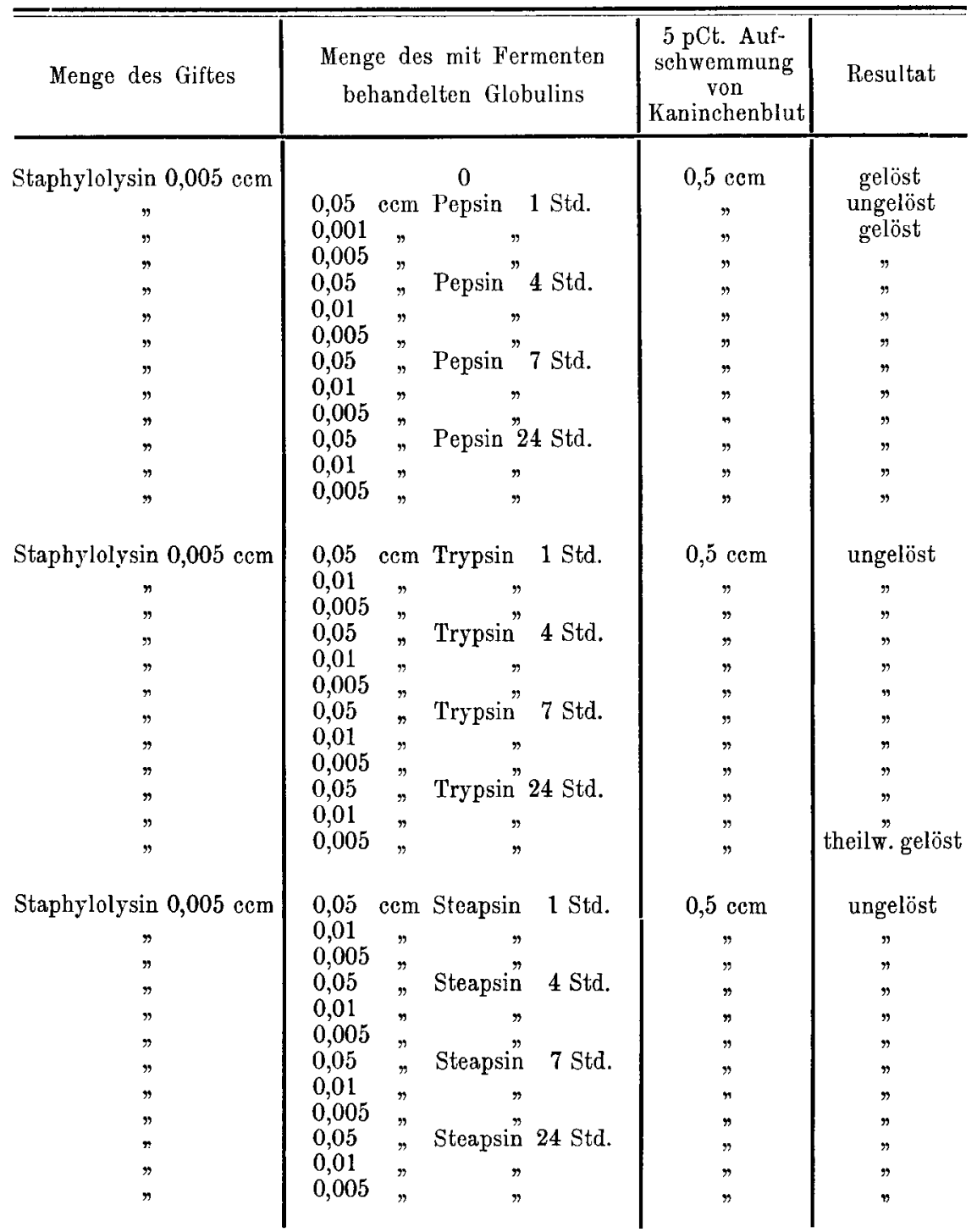

Anmerkung: Pepsin, Trypsin, Steapsin, 1 Std., 4 Std., 7 Std., 24 Std. bedeutet die Zeit der Einwirkung der betreffenden Fermente auf das Globulin.

Aus diesen Versuchen geht also der innige Zusammenhang nicht nur des Antistaphylolysins, was ja bereits nach meinen früheren Untersuchungen zu erwarten war, sondern auch des Antitetanolysins mit dem Globulin hervor, da ja durch Abbau und Veränderung des Eiweisses auch die antihämolytische Wirkung zerstört wird.

Für die Eiweissnatur dieser Antikörper spricht ausser den bereits angeführten Versuchen auch ihr Verhalten gegenüber höheren Temperaturen; beim Erhitzen des Globulins auf $70^{\circ} \mathrm{C}$ geht die hemmende Wirkung beinahe um das 10 fache des früheren Werthes zurück. 
Tabe 11 e IV.

\begin{tabular}{|c|c|c|c|}
\hline Menge des Giftes & Menge des Salzsïure-Globulin & $\begin{array}{l}5 \text { proc. Auf- } \\
\text { schwemmung } \\
\text { von } \\
\text { Kaninchenblut }\end{array}$ & Resultat \\
\hline $\begin{array}{c}\text { Tetanolysin } 0,0015 \mathrm{~g} \\
" \\
" \\
"\end{array}$ & \begin{tabular}{l}
\multicolumn{2}{c}{0} \\
$0,5 \quad \mathrm{ccm}$ \\
$0,1 \%$ \\
$0,05 \%$
\end{tabular} & $\begin{array}{c}0,5 \mathrm{ccm} \\
" \\
" \\
"\end{array}$ & $\begin{array}{l}\text { gelöst } \\
\text { Spur gelöst } \\
\text { gelöst } \\
"\end{array}$ \\
\hline $\begin{array}{c}\text { Staphylolysin } 0,005 \mathrm{ccm} \\
" \\
" \\
"\end{array}$ & $\begin{array}{l}0 \\
0,1 \\
0,05 \\
0,01 \%\end{array}$ & $\begin{array}{c}0,5 \mathrm{ccm} \\
" \\
" \\
"\end{array}$ & $\begin{array}{l}\text { gelöst } \\
\text { ungelöst } \\
\text { theilw. gelöst } \\
\text { gelöst }\end{array}$ \\
\hline
\end{tabular}

$\mathrm{Tab}$ a lle $\mathrm{V}$.

\begin{tabular}{|c|c|c|c|}
\hline Menge des Giftes & Menge des Alkali-Globulin & $\begin{array}{l}5 \text { proc. Auf- } \\
\text { schwemmung } \\
\text { von } \\
\text { Kaninchenblut }\end{array}$ & Resultat \\
\hline $\begin{array}{c}\text { Tetanolysin } 0,0015 \mathrm{~g} \\
" \\
" \\
"\end{array}$ & \begin{tabular}{l}
\multicolumn{2}{c}{0} \\
$0,5 \quad$ cem \\
$0,1 \quad \%$ \\
$0,05 \quad \%$
\end{tabular} & $\begin{array}{c}0,5 \mathrm{ccm} \\
" \\
" \\
"\end{array}$ & $\begin{array}{c}\text { gelöst } \\
\text { ungelöst } \\
\qquad " \\
"\end{array}$ \\
\hline $\begin{array}{c}\text { Staphylolysin } 0,005 \mathrm{ccm} \\
" \\
"\end{array}$ & \begin{tabular}{l}
\multicolumn{2}{c}{0} \\
$0,05 \quad \mathrm{cem}$ \\
$0,01 \quad "$ \\
$0,005 \%$
\end{tabular} & $\begin{array}{c}0,5 \mathrm{ccm} \\
" \\
" \\
"\end{array}$ & $\begin{array}{c}\text { gelöst } \\
\text { ungelöst } \\
\quad " \\
"\end{array}$ \\
\hline
\end{tabular}

\section{Ueber Alkohol und ätherlösliche antitetanolytische Substanzen des Serums.}

Complicirt wurden die eben angeführten Verhältnisse für das Tetanolysin jedoch durch den Umstand, dass es gelingt sowohl mit Alkohol als auch Aether aus dem Serum Antitetanolysin zu extrahiren. Aber nicht nur aus dem Serum sondern auch aus dem Globulin lässt sich diese hemmende Substanz extrahiren.

Von besonderem Interesse dürfte es aber sein, dass man sogar aus dem Albumin, das an und für sich gar nicht hemmt, durch Behandlung mit Aether einen schützenden Körper gewinnen kann. Daraus scheint mir hervorzugehen, dass es an der schützenden Wirkung desselben unbetheiligt ist. Dafür spricht auch vor Allem der Versuch, dass das mit Aether vollständig extrahirte Serum oder Globulin nichts von seiner antitetanolytischen Wirksamkeit verloren hat (Tab. VI).

Dass dieser Verlust des Antitetanolysins, wie er nach Behandlung des Globulins mit Salzsäure oder Pepsinsalzsäure eintritt nicht etwa auf einer Veränderung des Cholesterins, z. B. Umwandlung des Cholesterins in das nicht mehr hemmende Cholesterylchlorid beruht, dagegen sprechen zu diesem Zwecke angestellte Controlversuche. Eine Lösung von Cholesterin in Methylalkohol, die ca. $0,001 \mathrm{~g}$ im ccm enthält, wurde mit $19 \mathrm{ccm}$ $\mathrm{NaCl}-\mathrm{Lösung}$ verdünnt. Von dieser Lösung wurden entsprechende Mengen 
mit dem gleichen Volumen physiologischer Kochsalzlösung, oder mit $1 / 4$ Normal-Salzsäure, oder endlich mit 1/4 Normal-Salzsäure + Pepsin versetzt und 4 und 15 Stunden lang in den Brutschrank gestellt. Auch nach dieser Zeit war die Hemmung der mit Salzsäure und Pepsinsalzsäure versetzen Proben, die natürlich vor dem Versuche wieder neutralisirt wurden, genau so stark wie die durch die Controlprobe mit Kochsalzlösung (Tab. VII).

Tabelle VI.

\begin{tabular}{|c|c|c|c|c|c|}
\hline Menge des Giftes & & Men & ge der Zusätze & $\begin{array}{l}5 \text { proc. Auf- } \\
\text { schwemmung } \\
\text { von } \\
\text { Kaninchenblut }\end{array}$ & Resultat \\
\hline $\begin{aligned} \text { Tetanolysin } & 0,0015 \mathrm{~g} \\
& " \\
& " \\
& " \\
& \end{aligned}$ & $\begin{array}{l}0,1 \\
0,05 \\
0,01 \\
0,1 \\
0,05 \\
0,01\end{array}$ & $\begin{array}{l}\text { ecm } \\
" \\
" \\
"\end{array}$ & 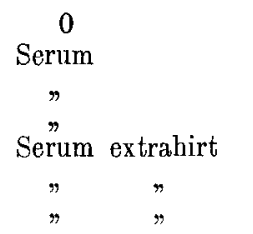 & $\begin{array}{c}0,5 \mathrm{ccm} \\
" \\
" \\
" \\
" \\
"\end{array}$ & $\begin{array}{l}\text { gelöst } \\
\text { ungelöst } \\
\text { fast gelöst } \\
\text { ungulöst } \\
\text { fast gelöst }\end{array}$ \\
\hline $\begin{array}{c}\text { Tetanolysin } 0,0015 \mathrm{~g} \\
" \\
" \\
" \\
"\end{array}$ & $\begin{array}{l}0,1 \\
0,05 \\
0,01 \\
0,1 \\
0,05 \\
0,01\end{array}$ & $\begin{array}{l}\mathrm{ccm} \\
" \\
"\end{array}$ & $\begin{array}{l}\text { Globulin } \\
\text { " } \\
\text { Globulin } \\
" \text { extrahirt } \\
"\end{array}$ & $\begin{array}{c}0,5 \mathrm{ccm} \\
" \\
" \\
" \\
" \\
"\end{array}$ & $\begin{array}{l}\text { ungelöst } \\
\text { theilw. gelöst } \\
\text { ungelöst } \\
\text { fast" gelöst }\end{array}$ \\
\hline
\end{tabular}

Tabelle VII.

\begin{tabular}{|c|c|c|c|}
\hline Menge des Giftes & Menge der Cholesterinlösung & $\begin{array}{c}5 \text { proc. Auf- } \\
\text { schwemmung } \\
\text { von } \\
\text { Kaninchenblut }\end{array}$ & Resultat \\
\hline $\begin{array}{r}\text { Tetanolysin } 0,0015 \mathrm{~g} \\
" \\
" \\
" \\
" \\
"\end{array}$ & 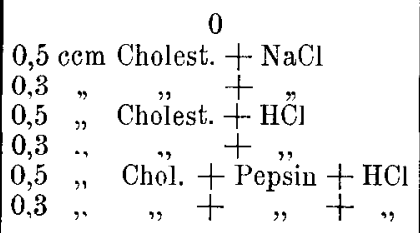 & $\begin{array}{c}0,5 \mathrm{ccm} \\
" \\
" \\
" \\
" \\
\Rightarrow \\
"\end{array}$ & $\begin{array}{c}\text { gelöst } \\
\text { ungelöst } \\
\text { " } \\
" \\
" \\
"\end{array}$ \\
\hline
\end{tabular}

\section{Mechanismus der Saponinwirkung.}

Wie aus den eben angeführten Versuchen hervorgeht, beruht die antitetanolytische Wirksamkeit des normalen Pferdeserums nicht auf dessen Cholesteringehalt; dagegen führten ähnliche mit Saponin angestellte Versuche zu dem Schlusse, dass die schützende Wirkung des Pferdeserums gegen Saponin in der That nur auf dessen Cholesteringehalt zurückzuführen sei.

Schon Ransom fand in seiner bereits erwähnten Arbeit über das Saponin, dass das hemmende Serum nach vollständiger Extraction mit Aether seine Schutzkraft verloren hatte, was eben darauf zurückzuführen ist, dass das Cholesterin entfernt ist. 
Meine eigenen Versuche mit Saponin, denen parallele Versuche mit Tetanolysin zum Vergleiche gegenüber gestellt wurden, ergaben ausser einer Bestätigung der Resultate von Ransom interessante Unterschiede gegenüber der antitetanolytischen Wirksamkeit des Serums.

$\mathrm{Zu}$ den Versuchen wurde das Saponin. album purissimum von Merck verwendet, und zwar eine mit Kochsalz hergestellte Lösung, die 0,000005 g Saponin im ccm enthielt. Von dieser Lösung wurde immer $1 \mathrm{ccm}$ zur Hämolyse von $0,5 \mathrm{ccm}$ gewaschenen Kaninchenblutes verwendet. Nachdem die hemmende Wirkung eines normalen Pferdeserums gegen Saponin und Tetanolysin festgestellt war, wurde aus diesem Serum das Globulin und Albumin durch Fällung mit Ammonsulfatlösung gewonnen und die beiden Eiweissniederschläge in einer dem Serum entsprechenden Menge Kochsalzlösung aufgenommen. Das Albumin und Globulin wurden hierauf auf Hemmung gegen die beiden Blutgifte geprüft.

Tabelle VIII.

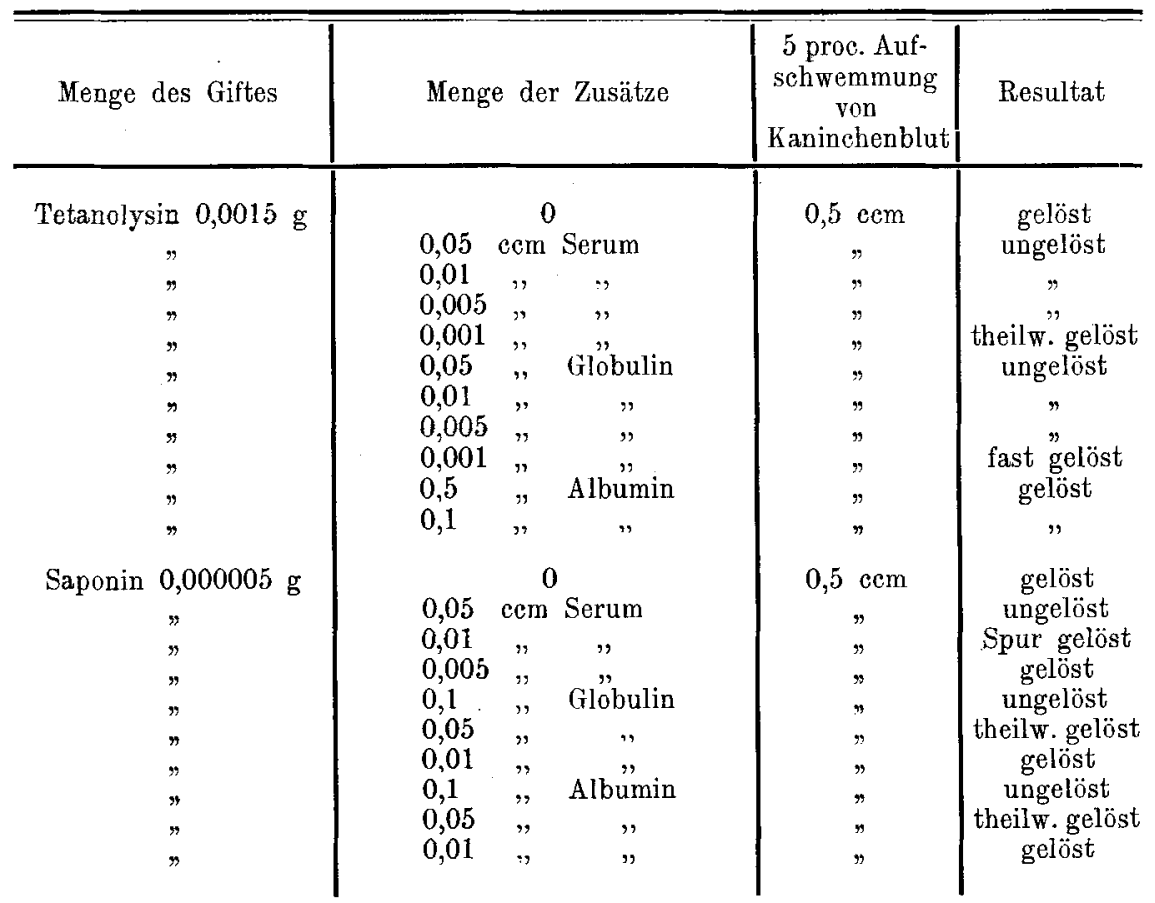

Es zeigt sich, dass beim Tetanolysin, wie bereits ausgeführt wurde, die Gesammthemmung des Serums an die Globulinfraction gebunden ist, das Albumin aber ganz unwirksam ist, während beim Saponin nicht nur das Globulin sondern auch das Albumin und zwar beide gleich stark hemmend wirkten. Die Hemmung jeder einzelnen Fraction war schwächer als die des Vollserums und zwar circa um die Hälfte, so dass aus der Addition der Wirkung der beiden Fractionen die Hemmung des Serums resultirt.

Das aus dem Serum gewonnene Globulin wurde wieder mit Salzsäure allein und mit Pepsin-Salzsäure behandelt. Wie zu erwarten war, 
Bedeutung der Lipoide für die antihämolytische Wirkung des Serums. 305

wurde die hemmende Wirkung des Globulins für das Tetanolysin aufgehoben, für das Saponin jedoch nicht beeinträchtigt.

T a belle $I X$.

\begin{tabular}{|c|c|c|c|}
\hline Menge des Giftes & Menge der Zusätze & $\begin{array}{l}5 \text { proc. Auf- } \\
\text { schwemmung } \\
\text { von } \\
\text { Kaninchenblut }\end{array}$ & Resultat \\
\hline $\begin{array}{c}\text { Tetanolysin } 0,0015 \mathrm{~g} \\
" \\
" \\
\text { Saponin } 0,000005 \mathrm{~g} \\
" \\
" \\
"\end{array}$ & 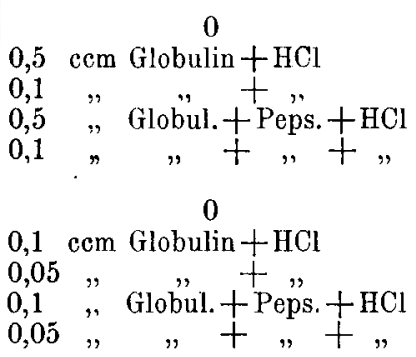 & $\begin{array}{c}0,5 \mathrm{ccm} \\
" \\
" \\
" \\
" \\
0,5 \mathrm{ccm} \\
" \\
" \\
" \\
"\end{array}$ & $\begin{array}{l}\text { gelöst } \\
\text { fast gelöst } \\
\text { gelöst } \\
\\
\quad \\
\text { gelöst } \\
\text { ungelöst } \\
\text { fast gelöst } \\
\text { ungelöst } \\
\text { fast gelöst }\end{array}$ \\
\hline
\end{tabular}

Sowohl das Serum als auch das Globulin wurden solange mit Aether extrahirt, als noch ein hemmender Körper in den Aether überging. Nach dieser Extraction wurde das Serum und Globulin wieder auf Hemmung geprüft. Die Wirkung für das Tetanusgift war erhalten geblieben, die für das Saponin verloren gegangen.

Tabelle X.

\begin{tabular}{|c|c|c|c|c|c|}
\hline Menge des Giftes & & Menge & der Zusätze & $\begin{array}{l}5 \text { proc. Auf- } \\
\text { sehwemmung } \\
\text { von } \\
\text { Kaninchenblut }\end{array}$ & Resultat \\
\hline $\begin{array}{c}\text { Tetanolysin } 0,0015 \mathrm{~g} \\
" \\
" \\
" \\
" \\
" \\
"\end{array}$ & $\begin{array}{l}0,05 \\
0,01 \\
0,00 \\
0,00 \\
0,05 \\
0,01 \\
0,00 \\
0,00\end{array}$ & $\begin{array}{l}\text { ccm } \\
5 " \\
1 \% \\
1 \% \\
5 " \\
1 \%\end{array}$ & $\begin{array}{c}0 \\
\text { Serum extrah. } \\
" \\
" \\
\text { Globulin extrah. } \\
" \\
" \\
"\end{array}$ & $\begin{array}{c}0,5 \mathrm{ccm} \\
" \\
" \\
" \\
" \\
" \\
" \\
"\end{array}$ & $\begin{array}{l}\text { gelöst } \\
\text { ungelöst } \\
\text { " } \\
\text { fast gelöst } \\
\text { ungelöst } \\
\text { " } \\
\text { fast "gelöst }\end{array}$ \\
\hline $\begin{array}{c}\text { Saponin } 0,000005 \mathrm{~g} \\
" \\
" \\
" \\
" \\
"\end{array}$ & $\begin{array}{l}0,5 \\
0,2 \\
0,1 \\
0,5 \\
0,2 \\
0,1\end{array}$ & $\begin{array}{c}\mathrm{ccm} \\
" \\
" \\
" \\
"\end{array}$ & $\begin{array}{c}0 \\
\text { Serum extrah. } \\
\text { Globulin extrah. } \\
\text { " }\end{array}$ & $\begin{array}{c}0,5 \mathrm{ccm} \\
" \\
" \\
" \\
" \\
"\end{array}$ & $\begin{array}{c}\text { gelöst } \\
" \\
" \\
" \\
"\end{array}$ \\
\hline
\end{tabular}

Ausser mit Aether wurde das Serum mit Alkohol extrahirt, d. h. es wurde das Serum mit der 4 fachen Menge absoluten Alkohols gefällt, rasch filtrirt, und der Eiweissniederschlag in der dem Serum entsprechenden Menge physiologischer Kochsalzlösung gelöst. Auch hier zeigt sich derselbe Untersehied zwischen Saponin und Tetanolysin wie in den früheren Versuchen. Im Gegensatze zu der Angabe von P. Th. Müller (17), 
der behauptet, dass das Serumeiweiss nach der Extraction mit Alkohol kein Antitetanolysin mehr enthalte, konnte ich feststellen, dass das Serumeiweiss auch nach der Extraction mit Alkohol so gut wie nichts von seiner antitetanolytischen Wirksamkeit verloren hatte, während dessen Schutzkraft gegen das Saponin fast vollständig aufgehoben war.

Tabelle XI.

\begin{tabular}{|c|c|c|c|}
\hline Menge des Giftes & Menge der Zusätze & $\begin{array}{c}5 \text { proc. Auf- } \\
\text { schwemmung } \\
\text { von } \\
\text { Kaninchenblut }\end{array}$ & Resultat \\
\hline $\begin{array}{c}\text { Tetanolysin } 0,0015 \mathrm{~g} \\
" \\
" \\
\text { Saponin } 0,000005 \mathrm{~g} \\
" \\
" \\
"\end{array}$ & 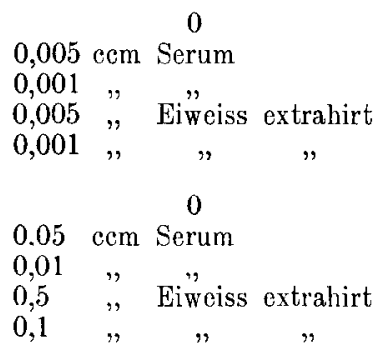 & $\begin{array}{c}0, \overline{0} \mathrm{ccm} \\
" \\
" \\
" \\
0,5 \mathrm{ccm} \\
" \\
" \\
"\end{array}$ & $\begin{array}{l}\text { gelöst } \\
\text { ungelöst } \\
\text { fast gelöst } \\
\text { ungelöst } \\
\text { fast gelöst } \\
\text { gelöst } \\
\text { ungelöst } \\
\text { Spur gelöst } \\
\text { fast gelöst } \\
\text { gelöst }\end{array}$ \\
\hline
\end{tabular}

Das alkoholische Filtrat nach dieser Fällung des Serums hemmte sowohl das T'tanolysin, wie bereits P. Th. Müller festgestellt hatte, als auch das Saponin.

Noch eine Beobachtung, die für den principiellen Unterschied zwischen Saponin- und Tetanolysin-Hemmung zeugt, möchte ich anführen. Bei der Untersuchung verschiedener normaler Pferdesera zeigten sich, wie schon erwähnt, sehr bedeutende Differenzen in deren Antitetanolysingehalt. Beim Saponin jedoch war bei den untersuehten Seris die Hemmungsgrenze fast constant, entsprechend den geringen Schwankungen des Cholesteringehaltes.

\section{Ueber die Bindungsarten des Tetanolysins.}

Dic Bindung des Tetanolysins an seinen specifischen Antikörper und an das Cholesterin findet sehr raseh statt. Schon nach ea. 15 Minuten langem $\Lambda$ ufenthalt eines solehen Gemisches im Brutschrank ist das Gift für rothe Blutkörperchen neutralisirt.

Die Art der Bindung zwischen Tetanolysin und Cholesterin scheint dieselbe zu sein, wie die zwischen Saponin und Cholesterin. Denn ebenso wie es Madsen und Noguchi (18) gelungen ist, dic Verbindung Cholesterin-Saponin durch Chloroform zu sprengen, ist es mir beim Tetanusgift ebenfalls möglich gewesen, das durch Cholesterin neutralisirte Tetanolysin durch Schütteln mit Chloroform wieder frei zu machen. Entsprechend der äusserst labilen Natur des Tetanolysins gelingen diese Versuche nur bei Beobachtung ganz bestimmter Bedingungen. Das blutlösende Gift wurde in diesen Versuchen mit einer entsprechenden Menge Cholesterin 20 Minuten jm Brutschrank digerirt. Nach dieser Zeit wurde dem Gemische immer eine Probe entnommen und mit Blut versetzt, um 
die erfolgte Neutralisation des Gemisches festzustellen. Das Gemisch Cholesterin-Tetanolysin wurde ganz kurze Zeit mit Chloroform geschüttelt --- wenn man zu lange schüttelt, so geht die lösende Fähigkeit des Tetanusgiftes verloren - die über dem Chloroform stehende Flüssigkeit filtrirt und dann noch zur ganz sicheren Vertreibung eventueller Spuren von Chloroform eine Zeit im Brutschrank gehalten. Erst dann wurde die Blutaufschwemmung zugesetzt. Bei solchen Versuchen gelang es zuweilen, das an Cholesterin gebundene Tetanolysin fast vollständig wieder frei $\mathrm{zu}$ machen, indem ein solches mit Chloroform geschütteltes Gemisch fast ebenso rasch die Blutkörperchen löste wie eine gleich starke reine Tetanolysinlösung.

In der früher citirten Arbeit von Madsen und Noguchi über die Bindung des Cholesterin-Saponins stellen diese Autoren eine Formel auf, nach der sie die Verbindung Cholesterin-Saponin als eine dissociable auffassen.

Die Trennung des Saponins aus seiner Verbindung mit Cholesterin nahmen sie in der Weise vor, dass sie eine auf Blutkörperchen inactive Mischung von Cholesterin-Saponin zur Trockene eindampften. Bei Behandlung des Trockenrückstandes mit Chloroform kann man das Cholesterin auszichen. Der chloroformunlösliche Rückstand giebt mit NaCl eine klare Lösung mit hämolytischer Eigenschaft. Auf Grund dieses Versuches und des Umstandes, dass man bei Behandlung eines für Blutkörperchen inactiven Cholesterin-Saponingemisches mit Salzsüure Zucker abspalten kann, sowie aus dem reinen Saponin, schliessen sie, dass das Saponin bei der Verbindung mit Cholesterin keine tiefergreifende Veränderung erleidet. Da es mir nun auch gelungen ist, das so empfindliche Tetanolysin aus einem in Bezug auf Blutkörperchen unwirksamen Cholesteringemisch wieder zu gewinnen, dürfte auch für diese Verbindung der Schluss berechtigt sein, dass es sich um eine lockere Bindung, vielleicht bloss um eine Adsorption handelt.

Versuche, welche angestellt wurden, um einen eventuellen Unterschied in dem Bindungsvermögen des Serums und dem aus diesem hergestellten Aetherextract für das Tetanolysin festzustellen, liessen eine solche Differenz nicht erkennen. Diejenige Menge beider Substanzen, welehe nach vorherigem 15 Minuten langem Digeriren mit dem Gifte die Blutkörperchen eben vor der Auflösung schützte, war bei gleichzeitigem Zusatz von Gift und Blut nicht im Stande zu schützen. Selbst die 10 fache Menge sowohl des Serums als des Aetherextractes konnten beide bei gleichzeitigem Zusatze von Blut und Gift nur theilweise Hemmung der Hämolyse bewirken. In Folge dessen war auch keine "Heilung" der bereits mit Lysin beladenen Blutkörperchen möglich.

Kraus und Iipschütz (19) fanden, dass sich das Antihämolysin in normalen und Immunseris qualitativ gleich verhalte und nur quantitativ verschieden sei. Sie konnten bei Zusatz sehr grosser Mengen Antihämolysin bei einem Tetanolysin noch bei gleichzeitigem Zusatz von Gift und Blut Aufhebung der Hämolyse bewirken und nach 5 Minuten auch noch Blutkörperchen heilen. Bei einem zweiten Tetanolysin waren sie auch mit den grössten Mengen nicht im Stande, Blutkörperchen zu heilen. 
Wenn Madsen (20) angiebt, dass es ihm auch noch nach $15 \mathrm{Mi}$ nuten gelingt, die Blutkörperchen zu heilen, so dürfte dies wohl auf die versehiedenen Versuchsbedingungen zurïrkzufiihren sein. Ich benützte zu meinen Versuchen ca. die doppelte Menge der einfach lösenden Dosis und arbeitete bei einer Temperatur von $36^{\circ} \mathrm{C}$, Iladsen nahm nur so viel Tetanusgift, dass eben Syse eintrat und experimentirte bei $13^{\circ}$. Unter diesen Umständen verläuft natürlich der Process der Giftbindung an die rothen Blutkörperehen viel langsamer.

\section{Ueber das Vorkommen und die Wirkungsweise des Cholesterins and seiner Ester im normalen Pferdeserum.}

lïne nähere Lntersuchung der im Serum vorkommenden fettartigen Körper wurde nach dem von Hürthle (21) angegebenen Verfahren vorgenommen. 2 Liter normales ron Blutkörperchen befreites Pferdeserum werden mit dem vierfachen Volumen 95 proc. Alkohols gefällt und über Nacht bei Zimmertemperatur stehen gelassen. Der Nlkohol wird dann abgesaugt und das Fiweiss wieder mit 8 Litern $9 \overline{5}$ proc. Alkohols versetzt und unter häufigem Umrühren acht Tage lang im Brutschrank extrahirt. Auch diese zweite alkoholische Jüsung wurde hierauf abgesaugt und das restliche Eiweiss mit einer Yischung von Alkohol und Aether zu gleichen Theilen zuerst 14 Tage lang bei Zimmertemperatur, dann durch 70 Stunden im Soxhlet extrahirt. Line so lange dauernde Extraction ist nach Jiebermann nothwendig, um das Lecithin aus seiner äusserst festen Verbindung mit liweiss den Lecithalbuninen zu befreien.

In der ersten stark gelb gefärbten $\Lambda$ lkoholfraction traten nach einiger Zeit nadelförmige Krystalle auf, die Hauptmasse dieser Krystalle fiel aber genau nach den Angaben von Hürthle in der zweiten Alkoholfraction in der Kälte aus. Während sich diese Krystalle nach und nach zu Boden senkten, zeigten sich auf der Oberfläche des Alkohols noch andere blättchenförmige Krystalle. In grösserer Ilenge wurden diese letzteren Krystalle aus dem dritten Alkohol-Aetherextract gewonnen.

Diese beiden Krystallisationsproducte stimmten sowohl in Bezugr auf ihre morphologischen Eigensehaften und ihre Löslichkeit als auch auf ihre Schnelzpunke - die nadelförmigen Krystalle schmolzen bei 43 bis $44^{\circ} \mathrm{C}$, die blättchenförmigen bei $77_{--70^{\circ}}$. mit den von Hürthle angegebenen Eigenschaften des (Oelsüure- und Palmitinsäure-Cholesterinesters so vollständig überein, dass sie wohl als der Oelsäure- und Palmitinsüure-Cholesterinester des Pferdeserums angesehen werden dürfen.

Die beiden so gewonnenen Cholesterinester wurden in Aether gelöst - die Löslichkeit ist eine weit geringere als die des Cholesterins und auf Hemmung des Tetanolysins untersucht. Selbst in den relativ sehr grossen Mengen von $0,002 \mathrm{~g}$ - das reine Cholesterin hebt in einer 500 Mal geringeren Menge die Hämolyse noch auf - war keine Spur von Hemmung durch diese beiden Körper zu constatiren.

W. Hausmann (22) hat als Erster beim Saponin auf diese interessanten l'crhältnisse hingewiesen. Lr untersuchte die verschiedensten 
Cholesterinderivate bezüglich ihrer hemmenden Wirkung gegen das Saponin und fand, dass die Derivate mit Besetzung der Hydroxylgruppe ganz unwirksam waren, die mit Aufhebung der doppelten Bindung nur mehr in geringem Masse hemmten. Er führt daher die hemmende Wirkung auf die Hydroxylgruppe zurück.

Aehnliche Versuche führten nach $\mathrm{H}$ ausmann mit verschiedenen Blutgiften, unter andern auch mit Tetanolysin, $\Lambda$ bderhalden und Count (23) aus und kamen zu demselben Resultat.

Alle diese Versuche wurden mit Cholesterinpräparaten verschiedener Herkunft ausgeführt. In meinen Versuchen wurden jedoch die aus dem Serum dargestellten Cholesterinester verwendet, doch auch diese erwiesen sich als ganz unwirksam. Während der dritte Alkohol-Aetherextract auch in grösserer Mengen keinen hemmenden Körper enthielt, erwiesen sich die alkoholischen Lösungen des I. und II. Filtrates, insbesondere des I. als hemmend.

Es wurden also das I. und II. Filtrat weiter untersucht. Die beiden Filtrate wurden im Vacuum auf ca. 300-400 ccm nahezu bis zur Syrupdicke eingeengt. Die so concentrirte alkoholische Lösung wurde nach Zuelzer (24) mit Aceton gefällt. Der abfiltrirte Niederschlag löste sich vollständig in Aether und erwies sich bei der Analyse als phosphorhaltig, so dass er als Lecithin angesprochen werden kann. Selbst in grösseren Mengen hemmte er die Hämolyse durch das 'Tetanusgift kaum merklich.

Das Filtrat der Acetonfällung wurde wieder eingeengt, beim Stehen desselben im Eisschrank scheiden sich fettartige Massen aus, die ebenfalls nicht hemmend wirkten. Das Filtrat zur Trockene eingedampft lieferte einen aus Fett, zahlreichen Fettsäurkrystallen und wenigen rhombischen Tafeln bestehenden Rückstand dieser Rückstand wurde mit wenig Chloroform versetzt, wobei sich nur ein Theil der fettartigen Masse löste, und die Chloroformlösung klar filtrirt. Dieselbe hemmte noch in ziemlich geringen Mengen die Hämolyse durch das Tetanusgift und gab von Cholesterinreactionen sowohl die Salkowski'sche als auch die von Liebermann. Nach diesen Ergebnissen ist die Annahme wohl berechtigt, dass im Serum ausser den Estern, die natürlich die Hauptmasse des vorhandenen Cholesterins darstellen, in Spuren auch freies Cholesterin vorkommt.

Allerdings handelt es sich nur um äusserst geringe Mengen, die sich unter den weitaus überwiegenden andern alkohollöslichen Bestandtheilen (Lecithine, Fette, Fettsäuren, Seifen) nur qualitativ nachweisen liessen. Nun wirkt aber das Cholesterin noch in den minimalsten chemisch nicht mehr nachweisbaren Quantitäten hemmend auf das Tetanolysin, so dass selbst diese geringen Mengen von Cholesterin genügen, um die schützende Wirkung der Aetherextracte des Serums zu erklären.

Wenn man das Serum mit Aether vollständig extrahirt und die gesammelten Aetherextracte auf das Volumen des Serums einengt, so hebt $0,005 \mathrm{ccm}$ dieses Aetherextractes die Hämolyse noch auf. Versuche mit reinem Cholesterin ergaben, dass $0,0000004 \mathrm{~g}$ genügten, um die Blutkörperchen vor der Auflösung durch das Tetanolysin zu schützen. Aus diesem Versuche lässt sich berechnen, dass ein Liter Serum nur einige Centigramme Cholesterin enthalten dürfte. 
Von allen im Serum enthaltenen fettartigen Körpern (Fette, Fettsäuren, Seifen, Lecithine, Cholesterin) kommt also nur dem letzteren eine schützende Wirkung gegen das Tetanolysin zu. Alle andern fettartigen Körper erwiesen sich in darauf hingerichteten Untersuchungen, als gar nicht oder nur in sehr geringem Grade hemmend.

Trotz dieser Schutzkraft des Cholesterins gegen das Tetanolysin, konnte ein principieller Unterschied in der Serumwirkung gegenüber dem Tetanusgift und gegenüber den anderen Blutgiften als deren Repräsentant das Saponin gelten kann, festgestellt werden. Dieser Unterschied liegt eben darin, dass beim letanolysin die hemmende Wirkung des Serums vor Allem auf einem Eiweisskörper beruht; ob daneben auch die aus dem Serum mit Aether, Petroläther, Alkohol extrahirbaren Stoffe unabhängig ron dem eigentlichen Antihämolysin ihre hemmende Wirkurg überhaupt entfalten, muss dahingestellt bleiben. Bei dem Saponin dagegen beruht die antihämolytische Serumwirkung ausschliesslich auf dessen Cholesteringehalt und dementsprechend hat das von Cholesterin befreite Serum seine schützende Wirkung verloren.

Wenn nun in früheren Untersuchungen (25) festgestellt werden konnte, dass sich Aetherextracte sowohl aus normalem Pferde- als auch Schweineserum gegen das Lysin des Vibrio Nasik unwirksam erwiesen, obwohl dieses Lysin durch Cholesterin gehemmt wird, so liegt der Grund für dieses Verhalten darin, dass das Cholesterin gegen das Hämolysin des Vibrio Nasik erst in bedeutend grösseren Mengen (ungefähr $100 \mathrm{Mal}$ mehr als beim Tetanolysin) hemmend wirkt und in den zu den Versuchen verwendeten Aethermengen (bis zu $2 \mathrm{ccm}$ ) zu wenig Cholesterin enthalten war.

Jedenfalls aber ergiebt sich, dass im Serum auch freies Cholesterin, wenn auch in sehr geringen Mengen, vorkommt. Dass sich darüber keine bestimmten $\Lambda$ ngaben in der litteratur vorfinden, ist wohl auf die verschwindend kleine Menge, in der dieser Körper im Blutserum nachweisbar ist, zurückzuführen. Wenn von Cholesterin im Serum die Rede ist, so handelt es sich gewöhnlich um die Cholesterinester, und auch Hürthle macht in seiner Arbeit über die Cholesterinester des Serums auf diesen Umstand aufmerksam. So wäre nach Hoppe-Seyler (26) Cholesterin in nicht unbeträchtlicher Menge im Serum enthalten. Hürthle macht darauf aufmerksam, dass das von Hoppe-Seyler gefundene Cholesterin aus dessen Estern stammt und er diesen Körper nur infolge seiner Darstellungsweise erhalten habe. Er extrahirte nämlich das Serum mit Aether and verseifte zur Entfernung der Fette den Aetherrückstand mit Kalilauge. Bei diesem Process werden aber auch die Cholesterinester verseift und so erhielt dann Hoppe-Seyler reines Cholesterin.

Was das Vorkommen des Cholesterins im Serum betrifft, so dürfte nach den vorliegenden Untersuchungen die Anschauung gerechtfertigt erscheinen, dass das Cholesterin im Blutserum mit Eiweiss gebunden, und zwar sowohl mit dem Globulin als auch mit dem Albumin vorkommt. Dafür spricht, dass beim Aussalzen mit Ammonsulfat das hemmende Lipoid mitgefällt wird und sowohl aus der Globulin- als auch aus der Albuminfraction mit Aether extrahirt werden kann. Ueber die 
Art einer solchen Verbindung lässt sich gegenwärtig nichts Sicheres aussagen; es kann vorläufig nicht sicher ausgeschlossen werden, ob die betreffenden Eiweisskörper durch physikalische Adsorption das Cholesterin festhalten.

\section{Beruht die antihämolytische Wirkung der Tetanusimmunsera anf ihrem Cholesteringehalte?}

Als Ergänzung zu den bisher ausgeführten Versuchen mögen noch einige vergleichende Versuche mit normalem Pferdeserum und mit Serum, das von mit Tetanustoxin immunisirten Pferden stammt, angeführt werden. Ein normales und ein Tetanus-Immunserum wurden beide auf ihre Hemmung für Tetanolysin eingewerthet, wobei sich zeigte, dass das Immunserum ungeführ tausend Mal stärker hemmte als das normale.

Tabelle XII.

\begin{tabular}{|c|c|c|c|}
\hline Menge des Giftes & Menge des Serums & $\begin{array}{l}5 \text { proc. Auf- } \\
\text { schwemmung } \\
\text { von } \\
\text { Kaninchenblut }\end{array}$ & Resultat \\
\hline $\begin{array}{c}\text { Tetanolysin } 0,0015 \mathrm{~g} \\
" \\
" \\
"\end{array}$ & \begin{tabular}{lcc}
\multicolumn{3}{c}{0} \\
0,5 & cem & Normalserum \\
0,1 & $"$ & \\
0,05 & $"$ & $"$ \\
0,01 &. & $"$
\end{tabular} & $\begin{array}{c}0,5 \mathrm{ccm} \\
" \\
" \\
" \\
"\end{array}$ & $\begin{array}{l}\text { gelöst } \\
\text { ungelöst } \\
\qquad " \\
\text { theilw. gelöst }\end{array}$ \\
\hline $\begin{array}{c}\text { Tetanolysin } 0,0015 \mathrm{~g} \\
" \\
" \\
"\end{array}$ & $\begin{array}{lcc}0,0005 & \text { ccm } & \text { Immunserum } \\
0,0001 & \# & " \\
0,00005 & \# & ? \\
0,00001 & \# & \end{array}$ & $\begin{array}{c}0,5 \mathrm{ccm} \\
" \\
" \\
"\end{array}$ & $\begin{array}{c}\text { ungelöst } \\
\text { fast gelöst }\end{array}$ \\
\hline
\end{tabular}

Die beiden Sera wurden hierauf vollständig mit Aether extrahirt, die gesammelten Aethermengen auf das Volumen des Serums gebracht und dann auf Hemmung geprüft. Wie zu erwarten war, wirkten die Aetherextracte aus dem normalen und dem Immunserum ganz gleich stark hemmend, d. h. die Cholesterinmengen im normalen und Immunserum sind die gleichen; die beiden extrahirten Sera hemmten ebenso stark wie vorher.

Tabelle XIII.

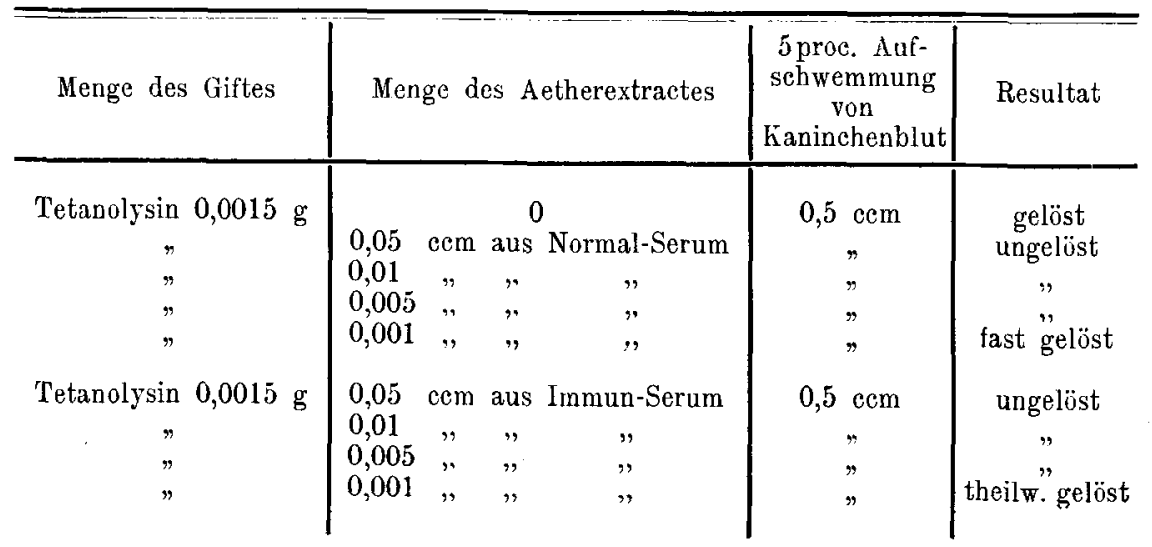


Aus diesen beiden extrahirten Seris wurde durch fractionirte Fällung mit Ammonsulfat das Euglobulin und Pseudoglobulin dargestellt und in einer dem Serum entsprechenden Menge physiologischer Kochsalzlösung gelöst. Die so gewonnenen Eiweisskörper wurden auf Hemmung gegen Tetanolysin geprüft.

Tabelle XIV.

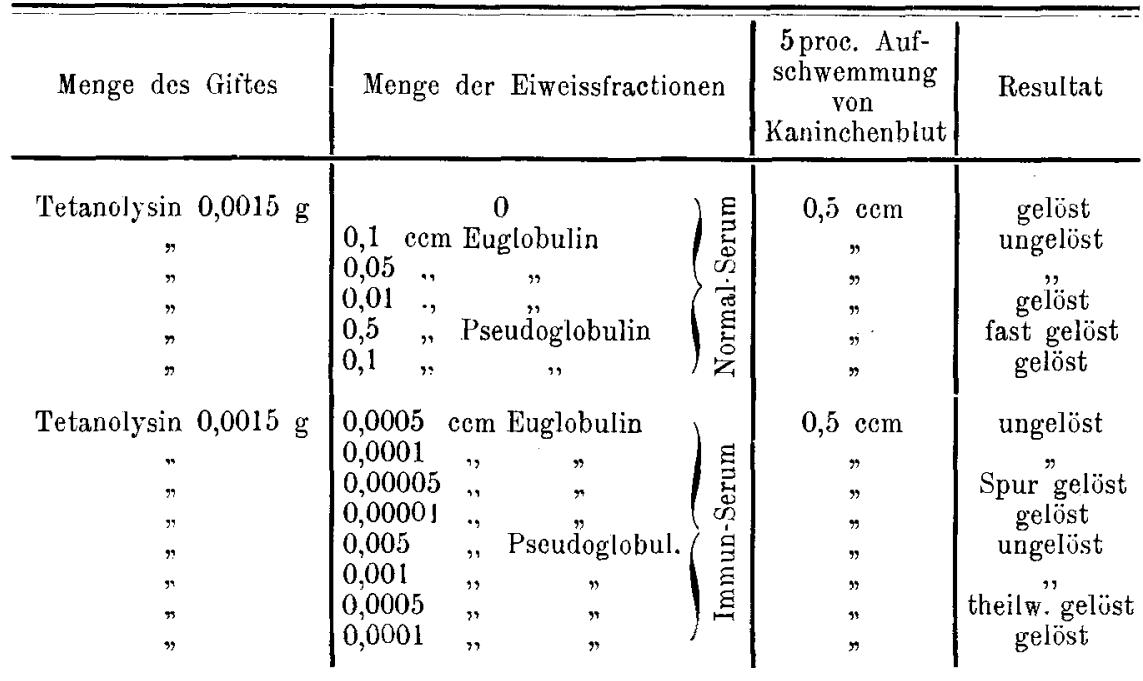

Beim Immunserum hemmte sowohl das Euglobulin als auch das Pseudoglobulin, beim normalen Serum nur das Euglobulin. Der N-Gehalt der beiden salzfreien Fractionen, nach Kjeldahl bestimmt, ergab in beiden Seris die gleichen Mengen Euglobulin und Pseudoglobulin, und zwar ca. 4 Mal so viel Euglobulin als Pseudoglobulin. Das Euglobulin des Immunserums hemmte in vierfacher Verdünnung nicht stärker als das Pseudoglobulin. Ob dieser Unterschied zwischen Normal- und Immunserum constant ist, lässt sich aus der geringen Anzahl der untersuchten Sera nicht mit Sicherheit sagen, zumal da die Sera, was den Gehalt der verschiedenen Fractionen an Antikörpern betrifft, nicht unbeträchtliehen Schwankungen unterliegen.

\section{Zusammenfassung.}

1. Aus dem normalen Pferdeserum kann die Hemmung des Serums quantitativ im Gesammtglobulin-Niederschlag erhalten werden und zwar sowohl für das Tetano- als auch das Staphylolysin; die Albuminfraction ist unwirksam. Dieses Globulin hemmt auch nach vollständiger Extraction mit Aether genau so stark wie vorher, wird aber durch Salzsäureund Salzsäure-Pepsin-Verdaung zerstört.

2. Aus dem an sich nicht hemmenden Albumin lässt sich mit Aether ebenfalls eine das Tetanolysin hemmende Substanz extrahiren, ebenso wie aus dem mit Pepsin verdauten, nicht mehr wirksamen Globulin.

3. Gegen die Hämolyse durch Saponin wirkt nicht nur das Globulin, sondern anch das Albumin. Aus beiden lässt sich mit Aether eine 
hemmende Substanz extrahiren; das extrahirte Eiweiss hemmt nicht mehr. Der gegen das Saponin wirksame Körper wird weder durch Salzsäure noch durch Pepsinsalzsäure geschädigt.

4. Das mit Aether vollständig extrahirte Serum hemmt noch in gleichem Maasse wie ursprünglich das Tetanolysin, nicht mehr aber das Saponin. Nach Fällung des Serums mit Alkohol ergiebt sich das gleiche Verhalten.

5. Der mit Aether extrahirbare fettartige Körper, welcher sowohl Tetanolysin als Saponin hemmt, ist Cholesterin. Ausser dieser Substanz ist im Serum ein eiweissartiger Antikörper für das Tetanolysin, nicht aber für das Saponin vorhanden. Nur auf diesem Liweisskörper beruht die Specifität der Serumwirkung.

6. Normale und Immunsera unterscheiden sich nicht bezüglich ihres Cholesteringehaltes.

\section{Litteratur.}

1. Overton, Studien über die Narkose. Jena 1901.

2. H. Meyer, Archiv f. exper. Pathologie. 1899.

3. Ransom, Deutscbe med. Wochenschr. 1901.

4. Noguchi, Centralbl. f. Bakteriologie. 1902.

5. P. Th. Müller, Centralbl. f. Bakteriologie. 1903.

6. H. Sachs, Centralbl. f. Bakteriologie. 1904.

7. Detre und Sellei, Wiener klin. Wochenschr. 1904, 1905.

8. Landsteiner und von Eisler, Wiener klin. Wochenschr. 1904 und Centralbl. f. Bakteriologie. 1905 .

9. Pascucci, Hofmeister's Beiträge. 1905.

10. Kraus und Clairmont, Wiener klin. Wochenschr. 1901.

11. Kraus und Clairmont, l. c.

12. M. Neisser, Deutsche med. Wochenschr. 1904.

13. H. Sachs, l. c.

14. von Eisler, Wiener klin. Wochenschr. 1905. No. 26, 30.

15. W. Hausmann, Hofmeister's Beiträge. 1905.

16. Abderhalden, Zeitschr. f. phys. Chemie. Bd. 25.

17. P. Th. Müller, l. c.

18. Madsen und Noguchi, Centralbl. f. Bakteriologie. Referate. 1905.

19. Kraus und Lipschütz, Zeitschr. f. Hygiene. 1904.

20. Madsen, Zeitschr. f. Hyg. Bd. 32 .

21. Hürthle, Zeitschr. f. phys. Chemie. Bd. 21.

22. W. Hausmann, l. c.

23. Abderhalden und Count, Zeitschr. f. experiment. Pathologie. Bd. 2.

24. Zülzer, Zeitschr. f. phys. Chemie. Bd. 27.

25. von Eisler, l. c.

26. Hoppe-Seyler, Med.-chem. Untersuchungen. Heft I. 1866. 